\title{
Teoria e método na análise de conjuntura
}

\author{
Sebastião C. Velasco e Cruz *
}

\begin{abstract}
RESUMO: O artigo versa sobre a lógica da análise de conjunturas políticas. Constatando o fato de que, em contraste com o observado na economia, a análise de conjuntura não constitui uma subárea diferenciada de investigação no campo da Ciência Política, o artigo traça um roteiro para a pesquisa e o ensino do tema, destacando dimensões gerais, problemas típicos e soluções alternativas com base no comentário de trabalhos representativos de autores clássicos (Marx, Weber, Tocqueville) e contemporâneos.
\end{abstract}

Palavras-chave: Teoria, metodologia, conjunturas políticas

O texto que se segue foi preparado para servir de referência a uma prova de aula em concurso de Livre docência. Isso se deu há vários anos. Desde então, muitas vezes pensei em retomá-lo para explorar mais a fundo os temas que ele aborda. Outros compromissos, outros interesses intelectuais, pura falta de tempo - por esse ou aquele motivo, nunca cheguei a fazê-lo. Considerando, porém, que talvez ele possa ter algum interesse para certa classe de leitor, resolvi tirá-lo da gaveta e divulgá-lo na forma em que veio à luz. Com alterações mínimas e alguns pequenos acréscimos, a versão presente reproduz fielmente, em seu conteúdo e retórica, o texto original.

"Teoria e método na análise de conjuntura: 50 minutos para dissertar sobre o tema".

Simples, não? Afinal de contas, análise de conjuntura é o que fazem cotidianamente políticos, articulistas e cidadãos informados, como exigência incontornável de suas atividades profissionais, ou - no caso destes últimos

*Docente do Departamento de Ciências Políticas, IFCH, Unicamp. E-mail: svelasco@uol.com.br 
- como parte do processo de formação de juízos sobre ocorrências, proposições e/ou indivíduos, que não se reduzam a meras projeções da subjetividade de quem os expressa. Ler jornais, cultivar o saber sobre instituições e usos no país, acompanhar com relativa atenção os movimentos de algumas personalidades públicas... nada muito complicado. Em caso de dificuldade, podemos sempre buscar a receita em um manual de Ciência Política. Certo?

Errado. Pensar assim é desconhecer a enorme distância que medeia entre o exercício de uma prática e a capacidade de explicitá-la, de enunciar os seus princípios subjacentes, esclarecê-la em seu alcance, suas implicações e seus pressupostos. Lembro-me de Michael Polany e da noção de conhecimento tácito que ele explora no livro Personal Knowledge. Lembrome também de Durkheim e do momento segundo que representou em sua obra a elaboração de As Regras do Método Sociológico, fruto de reflexão sobre os supostos de uma atividade prévia de pesquisa da qual $A$ Divisão do Trabalho Social constitui a realização maior e mais ambiciosa.

Naturalmente, em relação à análise de conjuntura, não disponho de nada remotamente parecido com as Regras do gigante Durkheim. E nem deveria ser preciso. O que se pede é a demonstração de domínio da teoria e da metodologia pertinente a essa área de problemas. Mas é precisamente aí que a dificuldade se ergue, quase intransponível: embora largamente praticada, a análise de conjuntura não se configura como um subcampo diferenciado e claramente reconhecido na Ciência Política, ou em sua prima, a Sociologia. Encontramos em ambas uma vasta e desigual literatura sobre crises, revoluções e fenômenos correlatos. Ela nos permite distinguir modalidades diferentes de conjunturas e, sobre algumas delas, oferece-nos modelos teóricos amplos e sofisticados - estou pensando, por exemplo, no livro de Michel Dobry, La Sociologie des Crises Politiques, que pretende dar conta de um tipo particular que ele denomina conjunturas fluidas ${ }^{1}$. Sobre a análise de conjuntura em geral, contudo, o silêncio impera.

No âmbito da economia não é assim. Desde a criação do Comitê de Pesquisa Econômica da Universidade de Harvard, em 1917, e da publicação anual de seu "barômetro econômico" até os dias de hoje, a análise conjuntural converteu-se para essa disciplina numa especialidade. E do esforço sistemático que, desde então, vem sendo realizado resultaram não apenas refinamentos teóricos e metodológicos indiscutíveis, mas a institucionalização de procedimentos sociais de produção e codificação de dados que alteraram profundamente a percepção que temos todos - estudiosos e leigos - da economia. Que se pense, por exemplo, na Contabilidade Nacional, a qual, segundo Giles- 
Gaston Granger (1955, p. 352), nasce e progride em conexão direta com a atividade dos conjunturalistas.

O contraste com a Ciência Política chega a ser chocante. Basta mencionar um índice: em suas mais de 1300 páginas, o dicionário de Norberto Bobbio não registra sequer uma entrada para o termo conjuntura. $E$ no entanto seria indispensável que o fizesse, porque este termo não tem nada de óbvio. Com efeito, o que entender por conjuntura? Uma configuração dada definida num tempo curto? Mas em que consiste o curto prazo em política? Um, dois, três meses? Três semanas, ou três dias? E qual a concepção de tempo com que operamos? O tempo cíclico, a exemplo dos primeiros ensaios conjunturalistas em economia? Um tempo cumulativo e ascendente, como em Marx, Engels, ou no Weber da teoria macro-histórica da racionalização? Ou o tempo neutro, operacional - ponhamos assim - que parece informar a atividade corriqueira do observador econômico contemporâneo, cujo problema básico consiste em, dadas certas hipóteses, antecipar o valor de algumas variáveis básicas - taxa de inflação, taxa de câmbio, taxa de juros, nível de atividade - num ponto determinado do tempo, a fim de habilitar o decisor a atuar sobre elas?

Evidentemente, o fato de não constar como um domínio distinto no corpo da Ciência Política não quer dizer que a análise de conjuntura seja estranha a essa disciplina, ou que a mesma nada tenha a dizer de útil sobre como praticá-la. Mas implica sustentar duas proposições embaraçosas para quem - como eu - deve dissertar sobre esta temática:

1) Implica reconhecer que nesse campo, como em tantos outros, predomina em nossa área o dissenso - a pluralidade de perspectivas teóricas e metodológicas;

2) Mais importante, implica afirmar que essa dissonância se mantém, na maior parte das vezes, implícita, dada a carência de esforços abrangentes e sistemáticos de teorização sobre a referida problemática.

Cabe então perguntar: se é assim, o que fazer?

Uma opção seria a de tomar um autor reconhecidamente importante que tenha se dedicado a esse tipo de atividade e, no cotejo de suas indicações específicas sobre a mesma, os exercícios práticos que tenha realizado e do quadro geral de seu pensamento, empreender um esforço concentrado de análise. Podemos imaginar facilmente alguns candidatos: Marx, com suas proposições gerais sobre as leis do desenvolvimento histórico e suas análises 
de conjunturas particulares, como o Dezoito Brumário, por exemplo; Gramsci, com suas notas sobre a análise de situações, a crise orgânica, o Cesarismo, a guerra de posição e guerra de movimentos, no Maquiavel, e com os escritos do período anterior ao seu encarceramento; em outra vertente, poderíamos eleger Weber, com sua sociologia sistemática e seus textos metodológicos, de um lado, e, de outro, seus estudos sobre contextos de crise, como os que esboçou sobre as revoluções russas, de 1905 e de 1917 (Weber 1981).

Essa alternativa, porém, lança-nos diante de dois problemas:

a) o da seleção entre os vários autores-candidatos;

b) o de efetuar um trabalho que não se limite a reproduzir o que tal autor formulou nesse ou naquele contexto, mas que nos leve a identificar tensões internas em seu pensamento; que nos permita avaliar o significado destas no movimento conjunto de sua obra; que nos autorize a expurgá-la, se possível, de seus elementos contraditórios, e habilite-nos a explorá-la nos limites de suas possibilidades. Os comentários de Elster (1985) sobre $O$ Dezoito Brumário e As Lutas de Classe na França e o artigo de Perry Anderson (197) sobre Gramsci podem ser citados como exercícios exemplares no gênero. A referência a eles justificase, porque evidencia esse fato capital: muito mais do que simples exposição de um material previamente organizado, essa alternativa implica a decomposição do objeto interpretado e um genuíno trabalho de elaboração teórica.

Possibilidade tão ou mais interessante seria a de tomar alguns casos particularmente ricos e/ou exitosos de análises de conjuntura, e logo proceder a um meticuloso exame visando destrinchá-los em seus procedimentos constitutivos e em sua lógica. Aqui tampouco os candidatos nos faltam. $O$ Dezoito Brumário poderia ser instrutivamente discutido em confronto com as reflexões sobre o mesmo episódio desenvolvidas por Tocqueville (1978), outro observador agudo daquela quadra histórica, num contraponto ao exercício que Raymond Aron desenvolve em seu livro sobre As Etapas do Pensamento Sociológico. Outro trabalho que poderia servir magnificamente a esse propósito é o livro admirável de George Brenan (1974) sobre a Guerra Civil Espanhola. Ou ainda o texto programático de Trotski sobre a revolução de $1905 \mathrm{com}$ seus desdobramentos, em Balanço e Perspectiva, e, naturalmente, a sua História da Revolução Russa, que serve de base a interessantes comentários de Stinchcomb em seu livro sobre os métodos teóricos na história social 
(1978). Aliás, o trabalho de Stinchcomb pode ser tomado como boa ilustração do tipo de produto que almejaríamos com essa atividade.

Nenhuma dessas opções, contudo, seria factível se não dispuséssemos de um roteiro prévio, um conjunto de indagações passíveis de serem dirigidas a cada autor, ou a cada um dos estudos considerados. Referido a dimensões que julgamos significativas de nosso problema, esse conjunto seria necessariamente provisório e deveria ser redefinido como um dos resultados previstos do próprio trabalho. Sintetizando, em alguma medida, a pré-compreensão de que dispomos do problema em causa, esse "roteiro" estaria a exercer uma dupla função: a um tempo, ele nos permitiria transitar ordenadamente pelos diferentes textos e nos advertiria que a natureza desse tipo de trabalho é precisamente esta: a do diálogo.

Sem qualquer pretensão de exaustividade, passo a arrolar agora algumas perguntas que uma listagem como essa deveria incorporar. Assim, caberia indagar:

1) Em cada caso, como são definidas internamente, e como são pensadas as relações entre as diferentes esferas do social?

2) Com base em que supostos são definidos em cada caso os atores significativos e de que maneira são especificadas as relações que entre eles se estabelecem? Com essa pergunta visamos dois problemas complexos e intimamente associados:

a) que propriedades um agente dado - individual ou coletivo deve apresentar para que o tomemos como ator numa conjuntura determinada?

b) como lidar com a questão da representação, entendida esta como fenômeno sociológico multiforme, e não como efeito institucionalmente produzido através da aplicação obediente da teoria normativa que tendamos a abraçar?

Nesse ponto, seria interessante retomar as indicações de Marx sobre a relação entre a pequena burguesia e os seus representantes ideológi$\cos ^{2}$. Ou ainda sua análise a respeito da crise da representação partidária que antecede o golpe de Luís Bonaparte (o abandono do "partido parlamentar da ordem" pela "massa extraparlamentar da burguesia"), cotejandoa com a que, pouco mais de meio século depois, Weber faria de fenômeno análogo (o descolamento que passa a se verificar entre os "as melhores mentes do liberalismo zemstvo" e seus representados, "os grandes proprietários de terra privada", quando estes começaram a sentir que os seus 
interesses econômicos estavam sob séria ameaça com o agravamento da crise de 1905 ( Weber 1981).

3) Na especificação das relações de força, como proceder à determinação do que venham a ser recursos de poder relevantes em cada uma das situações contempladas? Esses recursos são concebidos como um estoque previamente detido por cada ator, gerados no bojo de processos anteriores e externos aos conflitos em causa, ou, pelo contrário, em alguma medida ao menos, como resultado dos processos de luta cuja configuração caracteriza uma conjuntura dada?

4) Como é pensada, em cada caso, a prática política? Qual o peso conferido aos fatores ditos objetivos - condições estruturais, normas socioculturais internalizadas, por exemplo - e como se lida com a dimensão teleológica daquela prática: a formação de expectativas, a definição de objetivos, os procedimentos de cálculo e deliberação, a realização de movimentos táticos e a formulação de diretivas estratégicas? Objetivismo e subjetivismo entre essas duas posições que desde sempre polarizaram a teoria social como se situam as análises?

Nesse particular, seria interessante confrontar as análises finas de Marx sobre os embates políticos que marcaram a conjuntura de 1848 na França e o comentário ultra-objetivista que Engels faz das mesmas na introdução que escreveu para a reedição da obra ${ }^{3}$.

5) Em cada uma delas, qual o ponto de vista subjacente sobre a relação entre micro-fenômenos e macro-processos? Por acaso se admite que uma de tais dimensões possa subsumir a outra, ainda que em princípio, ou se considera que elas configuram dois planos analiticamente distintos, irredutíveis e interrelacionados?

Aqui, duas referências viriam a calhar: a passagem da História da Revolução Russa em que Trotski recria o dilema do soldado que se identifica com os rebeldes mas sabe que será severamente castigado se demonstrar isso em atos e a sublevação for sufocada ${ }^{4}$; o relato indiscreto, feito por Tocqueville, da repentina insolência da doméstica de um amigo seu que, no auge dos acontecimentos de 48, dizia ao servir o jantar da família: "Dimanche prochain c'est nous qui mangerons les ailes de poulet". 
6) Em que medida se contempla e de que maneira se trabalha a dimensão comunicativa da ação política? Qual a importância conferida à produção de mensagens que inere a todo ato político e qual o papel atribuído às diferentes modalidades de discurso, aos golpes e contra-golpes trocados no plano verbal?

Interrompo essa listagem ao constatar que o tempo estipulado para a preparação desta aula esgotou-se. E me pergunto, num sobressalto: Teoria e Método na análise de Conjuntura? Como será afinal minha aula?

Mas logo me dou conta de que a pergunta está deslocada. A aula já foi. E é assim mesmo que ela deve ser tomada: um pensar em voz alta. $\mathrm{O}$ desenho de um, ou dois cursos possíveis? Melhor ainda, a reiteração de um convite para um jogo apaixonante, se bem que por vezes arriscado.

\section{Notas}

1. Cf. Dobry 1986. Não menciono obras de grande envergadura como as Origens Sociais da Democracia e da ditadura, de Barrington Moore Jr. e States and Revolutions, de Theda Skocpol, porque ambas obedecem a uma perspectiva teórica que busca, explicitamente, fazer economia do "momento conjuntural" no estudo do fenômeno da revolução. O mesmo motivo leva-me a silenciar o esforço analítico daqueles que, como James C. Davis e Tedd Gurr, procuram identificar os determinantes das disposições sociopsicológicas que se expressam nas revoluções.

2. "Não se deve imaginar [...] que os representantes democráticos sejam na realidade todos shopkeepers (lojistas) ou defensores entusiásticos destes últimos [...]. O que os torna representantes da pequena burguesia é o fato de que sua mentalidade não ultrapassa os limites que esta não ultrapassa na vida, de que são consequentemente impelidos, teoricamente, para os mesmos problemas e soluções para os quais o interesse material e a posição social impelem, na prática, a pequena burguesia. Esta é, em geral, a relação que existe entre os representantes políticos e literários de uma classe e a classe que representam". ( Marx 1969, p. 48)

3. "O trabalho que aqui reeditamos foi o primeiro ensaio de Marx para explicar um fragmento da história contemporânea mediante sua concepção materialista [...] tratava-se, pois, de reduzir [...] os acontecimentos políticos a efeitos de causas que, em última instância, eram econômicas." "Na apreciação de acontecimentos e das séries de acontecimentos da história diária, jamais podemos remontar às últimas causas econômicas." (faltam-nos sempre as informações necessárias). Em conseqüência, o método materialista terá de se limitar, freqüentemente, a reduzir os conflitos políticos às luzes de interesses entre as classes sociais e as frações de classes existentes, determinadas pelo desenvolvimento econômico..." (Engels 1961, pp. 93-4.)

4. "os soldados, em conjunto, são tanto mais capazes de desviar as baionetas e passar para o lado do povo, quanto mais seguros estiverem de que os sublevados fazem 
verdadeiramente uma insurreição; de que não se trata de uma simples manifestação em seguida à qual a tropa voltará mais uma vez ao quartel e prestará contas de seus atos; de que o povo pode vencer se a ele se unirem; de que o triunfo pode assegurar sua impunidade e também melhorar as condições de sua existência". (Cf. Trotski, 1978, p. 118).

Recebido para publicação em Junho de 2000.

\section{Theory and method in conjunture analysis}

ABSTRACT: The article deals with the logic of the analysis of political conjunctures. Taking notice of the fact that conjuncture analysis does not exist as a distinct sub-area in the discipline of Political Science, the article presents some guidelines both for research and for teaching on this subject, pointing out general aspects of it, some typical problems, and alternative solutions to them. To this effect it draw on representative works by classics (Marx, Weber, Tocqueville) and contemporary authors.

\section{Bibliografia}

ANDERSON, Perry. "The Antinomies of Antonio Gramsci". New Left Review, no 100, 197.

BRENAN, Gerald. The spanish labyrinth. An account of the social and political background of the spanish civil war. Londres: Cambridge University Press, 1974 ( $1^{\text {a }}$ ed., 1943).

DOBRY, Michel. Sociologie des crises politiques. Paris: Presses de la Fondation Nationale des Sciences Politiques, 1986.

ELSTER, Jon. Making sense of Marx. Cambridge University Press, 1985.

ENGELS, F. "Introdução" a Marx, K. "As Lutas de Classe na França de 1848 a 1850", In: Obras Escolhidas de Marx e Engels, v. I, Rio de Janeiro: Editorial Vitória, 1961.

GRANGER, Giles-Gaston. Méthodologie économique, Paris: PUF, 1955.

MARX, K. O Dezoito Brumário e Cartas a Kugelmas. Rio de Janeiro: Paz e Terra, 1969.

STINCHCOMB, Arthur L. Theoretical methods in social history. New York: Academic Press, 1978.

TOCQUEVILLE, Alexis de. Souvenirs. Paris: Gallimard, 1978.

TROTSKI, Leon. A história da revolução russa. Rio de Janeiro: Paz e Terra, vol. I, 1978.

WEBER, Max. Sulla Russia - 1905/6/1917. Bologna: II Mulino, 1981. 